\title{
Retraction Note to: Correlation index of air pollutants and neurology patient care factors based on IOT
}

\section{Suying Liu ${ }^{1}$}

Published online: 3 November 2021

C) Saudi Society for Geosciences 2021

Retraction Note to: Arabian Journal of Geosciences (2021) 14: 1785

https://doi.org/10.1007/s12517-021-08065-4

The Editor-in-Chief and the Publisher have retracted this article because the content of this article is nonsensical. The peer review process was not carried out in accordance with the Publisher's peer review policy. The author has not responded to correspondence regarding this retraction.

The original article can be found online at https://doi.org/10.1007/ s12517-021-08065-4.

Suying Liu

YHT130723@163.com

1 Handan Central Hospital, Hebei 056000 Handan, China 